\title{
Metacommunity dynamics of amphibians in years with differing rainfall
}

\author{
Attila L. Péntek - Csaba F. Vad - Katalin Zsuga $\cdot$ Zsófia Horváth
}

Received: 9 July 2015/ Accepted: 28 August 2016

(C) Springer Science+Business Media Dordrecht 2016

\begin{abstract}
Many studies investigated the habitat preference and behaviour ecology of individual amphibian species while we know less about how their community assembly reflects changes in environmental factors, including the role of climatic extremes. Communitylevel studies also allow us to apply trait-based analyses that are crucial for a better understanding of the functioning of amphibian communities and metacommunities. In two years with contrasting rainfall (2012 and 2013), we found amphibian species in 85 different waterbodies of a heterogeneous landscape in Central Europe (Hungary). Within the metacommunity framework, the contributions of local, landscape and spatial variables to community assembly were assessed. We also measured the local extinction-colonisation rates in
\end{abstract}

Handling Editor: Piet Spaak.

Electronic supplementary material The online version of this article (doi:10.1007/s10452-016-9597-9) contains supplementary material, which is available to authorized users.

\section{A. L. Péntek $(\square)$}

Department of Zoology and Animal Ecology, Szent István University, Páter Károly u. 1, Gödöllő 2100, Hungary

e-mail: attila.petak@gmail.com

C. F. Vad · Z. Horváth

WasserCluster Lunz, Dr. Carl Kupelwieser Promenade 5, 3293 Lunz Am See, Austria

K. Zsuga

Fácán sor 56, Gödöllő 2100, Hungary the ponds for all species between the two years. To investigate the role of dispersal traits in explaining the spatial distribution of species, we studied the relationship between body size and the pure spatial fraction of variation. According to our results, the main drivers were the same in both the dry and wet year, but their relative contribution changed. Local variables played a predominant role in the assembly of the amphibian metacommunity. Spatial signals were more evident in the dry year. This implies not only the adverse effect of decreased connectivity due to the drying out of several habitats but also a loss of breeding sites for the studied amphibians. Local colonisation rates were higher in primarily terrestrial species (Hyla arborea, Pelobates fuscus, Bufo bufo) which only visit ponds during breeding. We found a negative relationship between the pure spatial effect and body size, suggesting an increased level of dispersal limitation in small-bodied species. Our results showed that while the strength and relative role of local and spatial processes changed between years, the role of dispersal traits in explaining the spatial distribution of species was similar. Specialisation to different habitats seems to be a major process in determining vertebrate metacommunities in landscapes. Dispersal traits of different species should be taken more into consideration in the practical conservation of amphibian habitats.

Keywords Pond - Dispersal limitation - Dispersal trait $\cdot$ Amphibian $\cdot$ Local colonisation · Metacommunity 


\section{Introduction}

The metacommunity concept is a useful way to understand the interactions and spatial dynamics of communities on a landscape scale. A metacommunity can be defined as a set of local communities that are linked by dispersal of multiple potentially interacting species (Leibold et al. 2004). Small aquatic landscape elements like ponds and pools are frequent models for metacommunity studies. They contribute to a high regional biodiversity, largely because of the high compositional dissimilarities (beta diversity) among sites (De Meester et al. 2005).

Amphibians are threatened worldwide: habitat destruction and fragmentation, introduced species, climate change and infectious diseases are all important reasons of global amphibian decline. A better understanding of temporal and spatial variation in their community structure is crucial for their long-term conservation (Houlahan et al. 2000; Marsh and Trenham 2001; Stuart et al. 2004). There is a growing evidence on the role of intensive human land use in their global decline and the importance of maintaining connectivity between the aquatic and terrestrial habitat patches in the landscape (e.g. Gibbs 1998; Vos and Chardon 1998; Lehtinen et al. 1999; Ficetola and De Bernardi 2004; Weyrauch and Grubb 2004; Curado et al. 2011). While today the habitat preferences of most European amphibian species are relatively well known (Bell 1977; Sinsch 1988), our knowledge on the drivers of the assembly and dynamics of their communities is much more limited, especially at the landscape scale.

Amphibians occupy two different niches through their life cycles, making them unique among vertebrates (Wilbur 1980). The usage of multiple niches has strong effects on amphibian colonisation and extinction dynamics, which deserve further study in a metapopulation and metacommunity framework. Dispersal is especially important for this group, as their aquatic breeding sites form discrete habitat patches in a terrestrial matrix, where most adult amphibians spend only a short time. Compared to other vertebrates, amphibians have much lower vagility and their dispersal movements strongly depend on habitat connectivity (Pechmann et al. 2001; Smith and Green 2005; Semlitsch 2008; De Bie et al. 2012). Dispersal limitation can differ highly among species (Smith and Green 2005): most species show high breeding site fidelity and stay within $1 \mathrm{~km}$ of their natal site (Semlitsch 2008). However, the maximum recorded distance covered by an amphibian was $34 \mathrm{~km}$ (Smith and Green 2006). The high rate of temporal turnover in amphibian communities has previously been documented in the literature (Werner et al. 2007b), which can be affected by the variability of hydrological conditions (Jakob et al. 2003, Gómez-Rodríguez et al. 2010). A high variability of ponds in a region can increase the persistence of metapopulations (GómezRodríguez et al. 2009), e.g. fishless habitats (including temporary ponds) can be used as refuges by amphibian species sensitive to fish predation (Hartel and Oellerer 2009). Even though temporary ponds have a critical importance for many amphibian species (Semlitsch 2003), they are less studied than permanent aquatic habitats (Schwartz and Jenkins 2000).

Local (e.g. water depth, salinity; Welborn et al. 1996; hydroperiod; Snodgrass et al. 2000; number of predators; Van Buskirk 2005; pond size, vegetation; Vági et al. 2013) and landscape variables (e.g. forest cover, proportion of open landscape; Van Buskirk 2005; Richter-Boix et al. 2007) are both important in shaping amphibian communities. When the terrestrial matrix does not limit dispersal and migration, the quality of aquatic habitats is the most important limiting factor for amphibians (Hartel et al. 2011). Spatial signals caused by the limited dispersal abilities of most amphibians can be evident in some landscapes (De Bie et al. 2012; Provete et al. 2014). Spatially structured local variables (Provete et al. 2014) and stochasticity (Delatorre et al. 2015) can also have an important role in shaping amphibian metacommunities.

Body size is increasingly considered to be a key trait in shaping metacommunity structure (Cottenie 2005; Soininen et al. 2007; Logue et al. 2011; De Bie et al. 2012). In actively dispersing taxa, dispersal abilities are thought to improve with body size, contributing to less dispersal limitation (Jenkins et al. 2007; Shurin et al. 2009). However, no study has tried so far to quantify the effect of species traits on the spatial structure of amphibian communities.

Here, we aimed to identify the main drivers of amphibian metacommunity structure in a Central European landscape that exhibits high heterogeneity of ponds and other landscape elements. We carried out a repeated survey in two consecutive years, which can be considered as extremes regarding their annual precipitation. First, we determined the relative 
contribution of local, landscape and spatial variables on the assembly of the communities. Second, we assessed local colonisation and extinction rates for each species between these two years, which has further implications for the dispersal abilities of the species. Finally, we investigated how species traits affect metacommunity organisation. For this, we studied the relationship between body size and the pure variation explained by local, landscape and spatial variables in the distribution of each species. We expected that larger body size would imply better dispersal abilities and hence lower effects of dispersal limitation for a given species.

\section{Materials and methods}

\section{Study area}

The study was conducted in the Southern Transdanubia, Hungary. The study area was ca. $600 \mathrm{~km}^{2}$ (Fig. 1). The surveyed area has two main parts: the Eastern Mecsek Hills (highest elevation: $682 \mathrm{~m}$ ) and the Tolna-Baranya Hills (including the Szekszárd Hills and the Geresd Hills, highest elevation: $301 \mathrm{~m}$ ). Larger permanent ponds are only typical in the foothills, while at higher elevations only small temporary pools and springs with permanent or semi-permanent streams are formed. Annual rainfall is 650 (in the east) and $710 \mathrm{~mm}$ (in the west). The landscape is dominated by native oak forests at lower elevations and beech forests at higher elevations and in cooler valleys. Plantations of non-native trees (Pinus nigra, Robinia pseudoacacia) also occur in the foothills. The forested areas are surrounded by intensively managed agricultural lands, especially corn fields and vineyards. Pastures, however, are not common in this region.

Field sampling

Surveys were conducted between March and July in 2012 and 2013. We explored the study area and sampled all waterbodies encountered. We included lakes, ponds, temporary pools, marshes and streams in our survey. We recorded the presence of amphibians in 85 waterbodies. Each waterbody was visited twice per year. First, we detected the breeding adults, eggs and larvae of the early breeding amphibians in March and April. Second, we focused on the adults, eggs and larvae of the prolonged breeders during the May-early July period and recorded the larvae and metamorphs of the early breeders. We used visual searching and hand netting to collect data: eggs and adults of frogs and
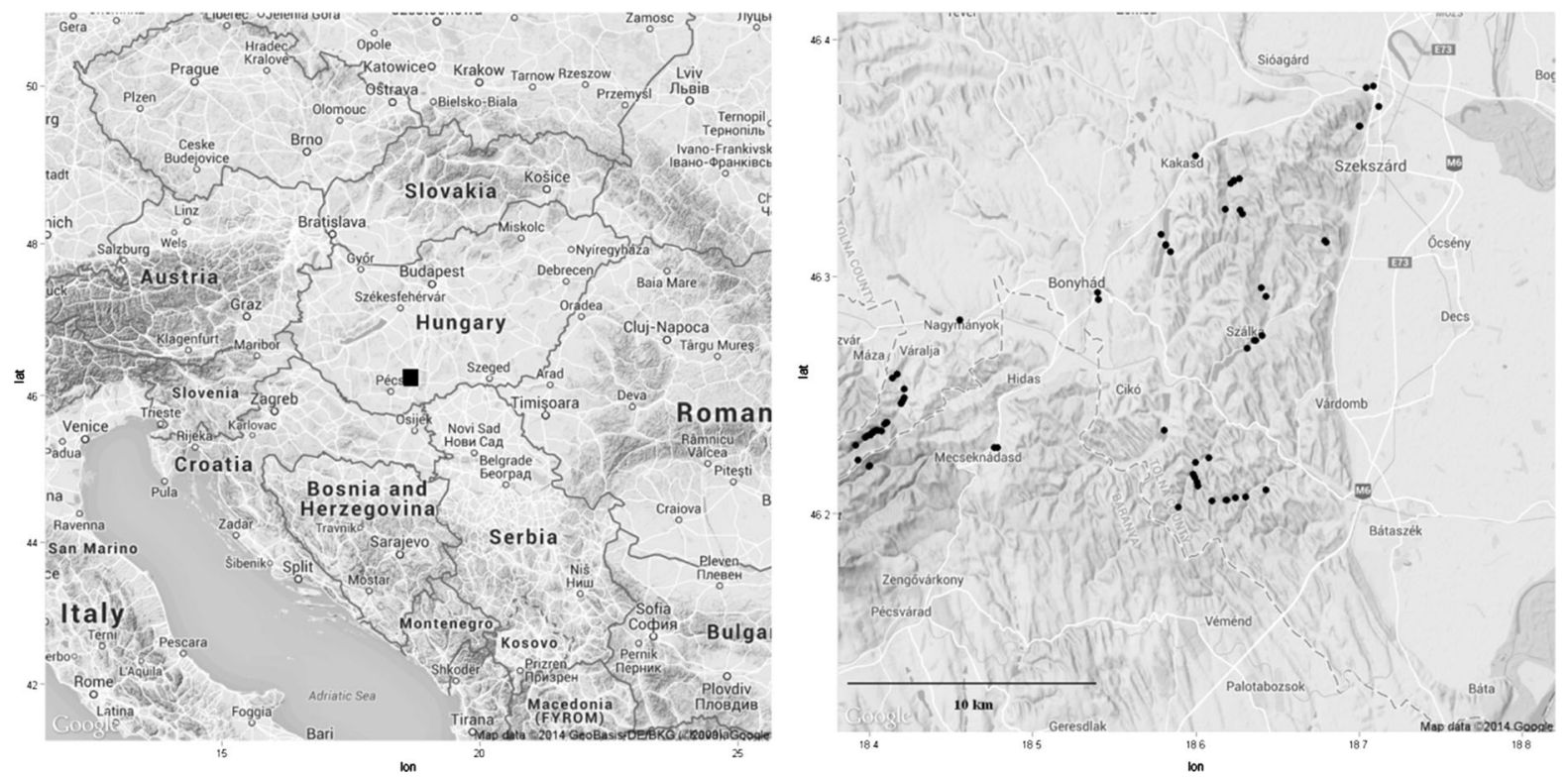

Fig. 1 Study area in southern Hungary with the sampling points for each year 
toads were recorded by visual observation, and larvae and adult newts by dip netting. We spent a maximum of 30 min searching for amphibians including all the microhabitats that were present in the ponds. Although we did not measure the probability of detection, the dip-netting method we used is a generally accepted procedure, and this duration should give representative results in accordance with other studies performed in small waterbodies (Rubbo and Kiesecker 2005; Rannap et al. 2010; Vági et al. 2013). Presenceabsence data were recorded for each amphibian species.

Eight local variables were measured at each sampling site: water temperature, hydroperiod length, flow type, transparency, water depth, surface area, vegetation cover and presence of fish (Table 1). We used three categories for hydroperiod length and transparency and two categories for flow type (standing or running water) as shown in Table 1. Hydroperiod length was estimated based on multiple surveys in each year. Water temperature was measured with a water thermometer at a depth of $15 \mathrm{~cm}$ in deeper waters or at the deepest location in habitats shallower than $15 \mathrm{~cm}$. For small temporary waters, surface area was calculated from length and width measurements with a tape measure. In case of larger permanent ponds marked on maps and satellite images, we used Google Earth Pro to measure the surface area (Google Inc. 2015). In streams, we surveyed the slow flowing sections that could be a potential habitat for amphibians. Water depth was measured at the deepest spot of the ponds with a measuring stick, and emergent vegetation cover (percentage from 0 to $100 \%$ ) was estimated by visual observation, always carried out by the first author. We used visual searching, hand netting and literature data to assess the presence of fish.

With Google Earth Pro, we measured the percentage of forested, agricultural and populated areas within a radius of $1000 \mathrm{~m}$ from each sampling site. Distance from the nearest forest patch and number of other waterbodies within $100 \mathrm{~m}$ were also calculated. Elevation and coordinates of the localities were recorded by a Garmin eTrex 10 GPS unit, and all measurements were validated with Google Earth. Elevation, land cover ratios, forest distance and the presence of nearby waterbodies were later grouped as landscape variables. The spatial location of sites was used in follow-up analyses to create spatial variables.
Data analysis

The number of large lakes in the region was very low $(N=3)$; moreover, these lakes were several orders of magnitude larger than the rest of the habitats. Therefore, we decided to exclude these lakes thus restricting our dataset to ponds, all being smaller than 5 ha in surface area, and other habitats of the same size (hereafter, all aquatic frog habitats are referred as to 'ponds'). Due to the rarity (less than 3 occurrences, Table 2) of Bufotes viridis in both years and of Pelobates fuscus in 2012, these species were excluded from the community analyses (but included in the calculation of species numbers). Community data are represented by the cumulative number of different species per year and pond, while environmental factors and numbers of different species numbers are averaged per year and pond. Prior to the analyses, water depth and surface area were ln-transformed, and vegetation cover was square root transformed.

To identify the main drivers of the amphibian community assembly, we constructed redundancy analysis (RDA) models using the package 'vegan' (Oksanen et al. 2012) in R software (R Development Core Team 2009). Separate RDA analyses were run for the two study years. RDA is a statistical method which allows using the information in an explanatory multivariate data matrix (here: local and landscape variables) to explain the variance in a response matrix (here: community matrix of amphibian species), and produces a constrained linear ordination of the response matrix, constrained by the explanatory variables. Significant variables $(p<0.05)$ among local and landscape variables were selected in a forward selection procedure, with the help of the 'ordistep' function of 'vegan' (based on 199 permutations). For obtaining spatial variables, we computed Principal Coordinates of Neighbourhood Matrix (PCNM) eigenvectors based on the spatial location of the sites sampled (Borcard and Legendre 2002). PCNM is a powerful tool to detect the spatial structure of communities. PCNM eigenvectors inform on the spatial arrangement of sites in a landscape based on their distance matrix, and they can be used in regression, ordination and other analyses in a similar way as other explanatory variables, e.g. environmental data (Oksanen et al. 2012). For attaining significant spatial variables, we ran a separate forward selection on the positive PCNM eigenvectors. To assess the 
Table 1 Local and landscape variables used in the analyses

\begin{tabular}{|c|c|c|c|c|c|c|c|c|}
\hline \multirow[t]{2}{*}{ Variables } & \multirow[t]{2}{*}{ Abbrev. } & \multicolumn{2}{|l|}{ Mean $\pm \mathrm{SE}$} & \multicolumn{2}{|l|}{ Range } & \multicolumn{2}{|c|}{ Median } & \multirow[t]{2}{*}{ Description } \\
\hline & & 2012 & 2013 & 2012 & 2013 & 2012 & 2013 & \\
\hline \multicolumn{9}{|l|}{ Local variables } \\
\hline Surface area $\left(\mathrm{m}^{2}\right)$ & Area & $1378.8 \pm 506.4$ & $1345.8 \pm 424.9$ & $0.1-15,000$ & $0.12-20,000$ & 17.5 & 16 & \\
\hline Water depth (cm) & Depth & $41.6 \pm 5.3$ & $39.2 \pm 4.7$ & $2-100$ & $2-100$ & 30 & 15 & \\
\hline $\begin{array}{l}\text { Vegetation cover } \\
(\%)\end{array}$ & Vegcov & $28.9 \pm 5.0$ & $24.3 \pm 3.7$ & 0-99 & $0-93$ & 5 & 3.5 & \\
\hline $\begin{array}{l}\text { Transparency } \\
\text { (nominal) }\end{array}$ & $\mathrm{t}$ & - & - & - & - & - & - & $\begin{array}{l}1 \text {-transparent } \\
2 \text {-medium } \\
3 \text {-turbid }\end{array}$ \\
\hline $\begin{array}{l}\text { Flow type } \\
\text { (nominal) }\end{array}$ & $\mathrm{f}$ & - & - & - & - & - & - & $\begin{array}{l}1 \text { - standing (lentic) } \\
2 \text {-running (lotic) }\end{array}$ \\
\hline $\begin{array}{l}\text { Hydroperiod } \\
\text { (nominal) }\end{array}$ & $\mathrm{HP}$ & - & - & - & - & - & - & $\begin{array}{l}\text { 1-short } \\
\text { hydroperiod } \\
\text { (shorter than } \\
3 \text { month) } \\
\text { 2-semipermanent } \\
\text { water } \\
\text { (3-12 month) } \\
\text { 3-permanent water }\end{array}$ \\
\hline $\begin{array}{l}\text { Fish presence } \\
\text { (binary) }\end{array}$ & Fish & - & - & - & - & - & - & $\begin{array}{l}0 \text {-fish absent } \\
1 \text {-fish present }\end{array}$ \\
\hline Temperature $\left({ }^{\circ} \mathrm{C}\right)$ & $\mathrm{T}$ & $18.3 \pm 0.7$ & $13.4 \pm 0.7$ & $10-30$ & $4-33$ & 18 & 13 & \\
\hline \multicolumn{9}{|l|}{ Landscape variables } \\
\hline Altitude (m) & alt & $172 \pm 9.1$ & $194 \pm 9.9$ & $88-327$ & $88-445$ & 155 & 166.5 & \\
\hline \multirow[t]{3}{*}{ Land cover $(\%)$} & agr & $13.8 \pm 2.7$ & $10.4 \pm 1.7$ & $0-95$ & $0-53$ & 5 & 2.5 & $\begin{array}{l}\text { Agricultural cover } \\
(\%) \text { within a radius } \\
\text { of } 1000 \mathrm{~m}\end{array}$ \\
\hline & for & $53.5 \pm 5.3$ & $61.6 \pm 4.4$ & $1-99$ & $1-99$ & 57 & 78 & $\begin{array}{l}\text { Forest cover }(\%) \\
\text { within a radius of } \\
1000 \mathrm{~m}\end{array}$ \\
\hline & settl & $6.0 \pm 1.2$ & $4.6 \pm 0.9$ & $0-33$ & $0-33$ & 1 & 0 & $\begin{array}{l}\text { Settlement cover } \\
(\%) \text { within a radius } \\
\text { of } 1000 \mathrm{~m}\end{array}$ \\
\hline $\begin{array}{l}\text { Forest distance } \\
\text { (m) }\end{array}$ & for_dist & - & - & $0-880$ & $0-880$ & 0 & 0 & $\begin{array}{l}\text { Distance of the } \\
\text { nearest forest } \\
\text { patch }\end{array}$ \\
\hline $\begin{array}{l}\text { Other } \\
\text { waterbodies } \\
\text { within } 100 \mathrm{~m} \\
\text { (nominal) }\end{array}$ & hab100 & - & - & - & - & - & - & $\begin{array}{l}0 \text { - absent } \\
1 \text { - present }\end{array}$ \\
\hline
\end{tabular}

contribution of the significant variable sets to metacommunity assembly, we used variation partitioning with the package 'vegan' (Oksanen et al. 2012), for which variables were grouped as local, landscape and spatial variables (Supplementary Tables 3-4 in Online Resources). Variance partitioning regarding community structure and species richness was done for each year individually, and the percentage of variation explained by each fraction was illustrated in respective Venn diagrams (package 'vegan', R software).

In our study, species richness means the mean number of amphibian species per pond per year. To identify the main drivers of species richness, we used a linear model and the stepwise model selection 
Table 2 Total number of ponds and the number of occupied ponds by the different amphibian species (the ratio of occupancy is given in brackets) in the two study years, along with the local extinction and colonisation rates of habitat occupancy between years (the latter are only calculated for frogs)

\begin{tabular}{|c|c|c|c|c|c|}
\hline & \multirow[t]{2}{*}{ Abbreviation } & \multicolumn{2}{|c|}{ Number of waterbodies } & \multirow[t]{2}{*}{ Local extinction (\%) } & \multirow[t]{2}{*}{ Local colonisation $(\%)$} \\
\hline & & 2012 & 2013 & & \\
\hline Total & & 51 & 70 & & \\
\hline Bombina bombina & Bom_bom & $12(23.5 \%)$ & $12(17.14 \%)$ & 22 & 0 \\
\hline Bombina variegata & Bom_var & $19(37.3 \%)$ & $37(52.86 \%)$ & 14 & 0 \\
\hline Bufo bufo & Buf_buf & $7(13.7 \%)$ & $17(24.29 \%)$ & 1 & 46 \\
\hline Bufotes viridis & Buf_vir & $2(3.90 \%)$ & $1(1.43 \%)$ & - & - \\
\hline Hyla arborea & Hyl_arb & $3(5.88 \%)$ & $9(12.86 \%)$ & 33 & 67 \\
\hline Lissotriton vulgaris & Lis_vul & $6(11.8 \%)$ & $17(24.29 \%)$ & - & - \\
\hline Pelobates fuscus & Pel_fus & $1(1.96 \%)$ & $8(11.43 \%)$ & 0 & 83 \\
\hline Pelophylax esculentus complex & Pel_esc & $26(50.98 \%)$ & $33(47.14 \%)$ & 0 & 0 \\
\hline Rana dalmatina & Ran_dal & $22(43.14 \%)$ & $34(48.57 \%)$ & 22 & 19 \\
\hline Triturus dobrogicus & Tri_dob & $0(0 \%)$ & $4(5.71 \%)$ & - & - \\
\hline
\end{tabular}

'stepAIC' (with direction 'both' and with 1000 permutation steps) in 'MASS' (Venables and Ripley 2002) package for identifying significant local and landscape factors. Separate multiple linear regression analyses were run for the two study years. Significant PCNM eigenvectors were selected, and afterwards, variation partitioning was applied with the same approach as in the community (presence-absence) data analyses described above.

To explore metapopulation dynamics among the frog species, we calculated the rate of local extinction and colonisation between the two years for ponds that held water in both years (Richter-Boix et al. 2007). We measured the rate of local extinction (i.e. absence at the pond scale) as the number of sites occupied in the first year that were unoccupied in the second year divided by the total number of sites occupied in both years. Local colonisation rate was calculated as the number of unoccupied sites in the first year that were occupied in the second year divided by the total number of sites occupied in both years. Although we compare data only from two years, this method should already provide relevant information on the differences between the interannual pond occupancy of the species we studied, as well as their relative colonisation abilities.

Then, we investigated how body size (a key dispersal trait) can shape metacommunity patterns. As the body size of species, we used the mean snoutvent length data published by Berninghausen and
Berninghausen (1997). First, we ran separate variation partitioning analyses for each frog species. For this, significant local, landscape and spatial variables (PCNM eigenvectors) were identified with logistic general linear models, with the 'stepAIC' function based on the AIC criterion (with direction 'both' and with 1000 permutation steps). Second, to test the relationship between the body size of frogs and the pure local, landscape and spatial variation (resulting from the previous variation partitioning analyses) in their distribution (related to colonisation ability) in the two years, we used linear models with the mean body size data of the respective frog species as the dependent variable and their pure local, landscape or spatial variation as the independent variable.

\section{Results}

The number of flooded ponds considerably increased in the second year, which was related to the increased annual precipitation and the related filling of shallow temporary marshes, many of which were dry in the first year (Table 2). Altogether ten amphibian species were found. The most common taxa were from the Pelophylax esculentus complex, or species identified as Rana dalmatina and Bombina variegata. All occurred in approximately half of the ponds for at least one year (Table 2). Bufo bufo, Hyla arborea, Pelobates fuscus, Lissotriton vulgaris and Triturus 
dobrogicus were found in a much higher number of ponds in 2013 than in 2012 (Supplementary Table 1 in Online Resources). There was no difference in the number of occurrences of B. bombina between the two years. Bufotes viridis was rare in the region, occurring only in 1-2 ponds.

The forward selection procedure of the RDA identified the significant effect $(p<0.05)$ of water depth and vegetation cover on the community assembly of species in both years. In addition to them, temperature, the presence of fish (in 2012) and hydroperiod together with transparency (in 2013) were found as significant local variables. In 2012, only altitude was a significant landscape variable, while in 2013, both the distance from the nearest forest patch and the ratio of agricultural land cover within $1000 \mathrm{~m}$ were significant (Supplementary Tables 3-4 in Online Resources). In the RDA ordination of community composition in 2012, the five constrained components with positive eigenvalues explained $43.3 \%$ of the total variation (eigenvalues of the first three components: $0.265,0.131$ and 0.030). In 2013, eight constrained components had positive eigenvalues, explaining $49.9 \%$ of the total community variation (eigenvalues of the first three components: 0.492, 0.131 and 0.095 ). There was a general difference between the habitat preference of $B$. variegata and all the other species: B. variegata preferred shallow and temporary ponds at relatively high altitudes and was hence clearly separated in the RDA plots in both years (Fig. 2). Apart from minor differences among the two years, B. bombina, $H$. aborea, $P$. fuscus, $L$. vulgaris and $T$. dobrogicus were overall primarily associated with highly vegetated ponds. $B$. bufo and $R$. dalmatina tended to be associated with permanent, deep ponds.

According to variation partitioning, local effects (attributable to the significant local variables) played a predominant role in explaining community composition in both years (20 and $18 \%$; Fig. 3). Landscape variables explained only low unique variation in the data (1 and $2 \%$ ). The pure effect of space (attributable to the significant PCNM eigenvectors) was higher in the dry $(2012 ; 6 \%)$ than in the wet year $(2013 ; 1 \%)$. Our variation partitioning models explained almost half of the total variation (43\% in 2012 and $45 \%$ in 2013).

Local, spatial and landscape variables all had a significant effect $(p<0.05)$ on species richness. Water depth, vegetation cover, hydroperiod and settlement cover within a radius of $1000 \mathrm{~m}$ appeared to be significant in both years. Additionally, temperature proved to be significant in 2012 (resembling our results based on community data). In parallel with the results on community composition, variation partitioning revealed a lower spatial effect on species richness in the wet year, while the role of local effect considerably increased (from 24 to $32 \%$; Fig. 3).

Local colonisation rates were high in the case of $P$. fuscus (83\%) and $H$. arborea $(67 \%)$ and low $(<20 \%)$ in water frogs (B. bombina, B. variegata, $P$. esculentus complex). Local extinction rate was also high in the case of Hyla arborea (33\%) (Table 2; Supplementary Table 2 in Online Resources; Fig. 4).

The relationship between the pure local effect and body size was significantly positive in 2012 $\left(R^{2}=0.69, p=0.04\right)$, with a similar, but non-significant trend in $2013\left(R^{2}=0.14, p>0.05\right)$. We found no significant relationship between the pure spatial effect and body size $\left(R^{2}=0.35, p>0.05\right.$ in 2012 ; $R^{2}=0.15, p>0.05$ in 2013), but the trend was negative in both years (Fig. 5). The pure spatial variation was lower in larger taxa (B. bufo, $P$. esculentus complex, $R$. dalmatina) than in smaller ones (B. bombina, H. arborea). In addition, we found a similar non-significant negative relationship between the pure regional effect and body length $\left(R^{2}=0.27\right.$, $p>0.05$ in 2012; $R^{2}=0.25, p>0.05$ in 2013).

\section{Discussion}

Relative importance of metacommunity processes

In our survey, we found all amphibian species which occur in the study region (Puky et al. 2005). We found considerable differences in the contribution of local and spatial variables between the dry and wet year. Local, landscape and spatial variables all appeared to be significant determinants of the amphibian metacommunity structure and species richness, among which local and spatial variables had the strongest effect.

Local variables (including depth, vegetation cover and hydroperiod) were particularly important, explaining the highest amount of variation in the data. Water depth is a good indicator of pond size and permanence, usually favouring more species (Fryer 1985; Laan and Verboom 1990; Oertli et al. 2002). Large open-canopy ponds are associated with higher 


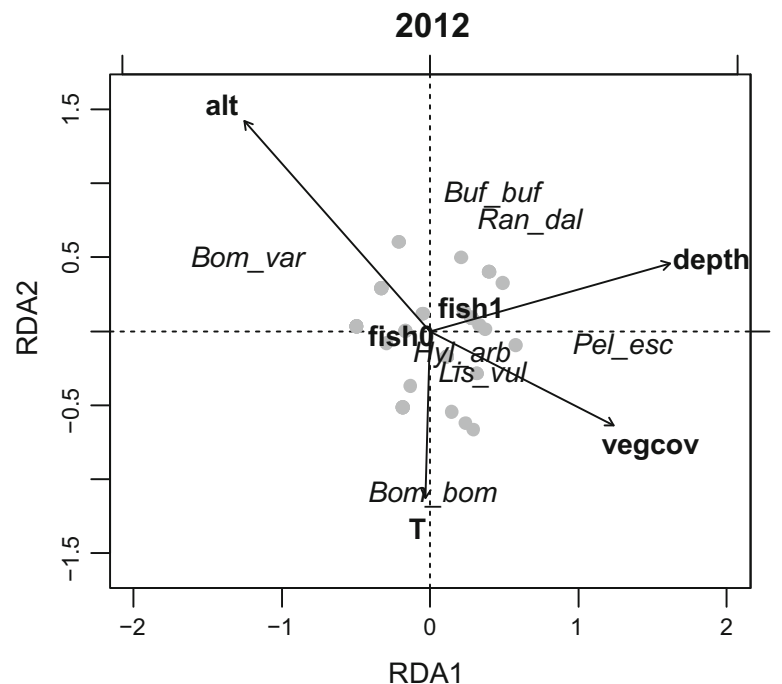

Fig. 2 Results of the redundancy analyses (RDA) in 2012 and 2013. Abbreviations for local and landscape variables (bold letters, continuous variables are indicated with arrows, while factorial ones only with labels indicating each level) are listed in

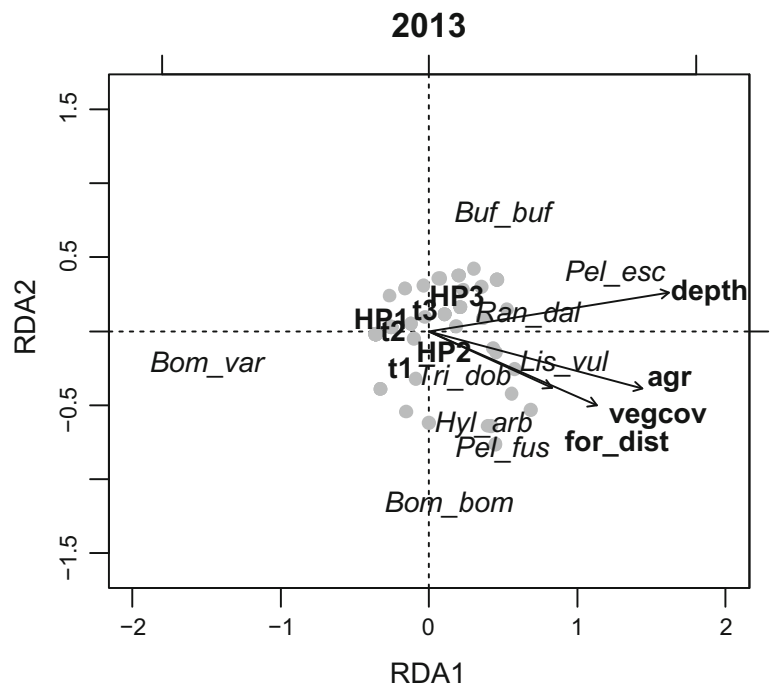

Table 1. Only significant variables $(p<0.05)$ are presented on the plots. Abbreviations for species (indicated only by labels with italic formatting) are derived from the first three letters of the genus and species name. Points stand for samples (i.e. ponds)

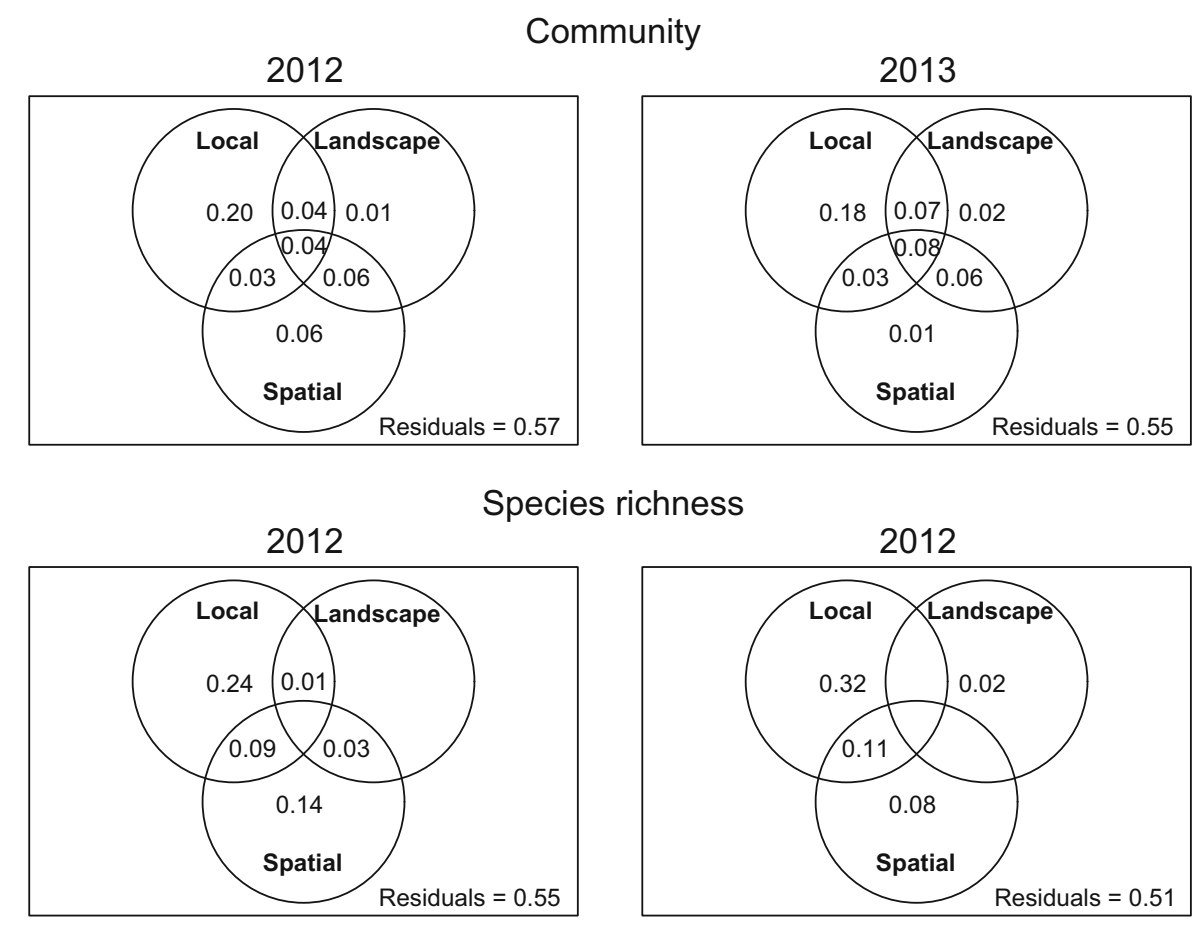

Fig. 3 Variation explained by local, landscape and spatial effects in community structure and species richness in 2012 and 2013 , based on variation partitioning. All pure effects (individual fractions) were significant $(p<0.05)$, except for the landscape effect in 2012

primary productivity, including high standing crop and diversity of periphyton and macrophytes (Skelly et al. 2002), which can be beneficial for amphibians as a refuge from predators and substrate for eggs (Strijbosch 1979). Hydroperiod is another widely cited factor influencing amphibian species richness 


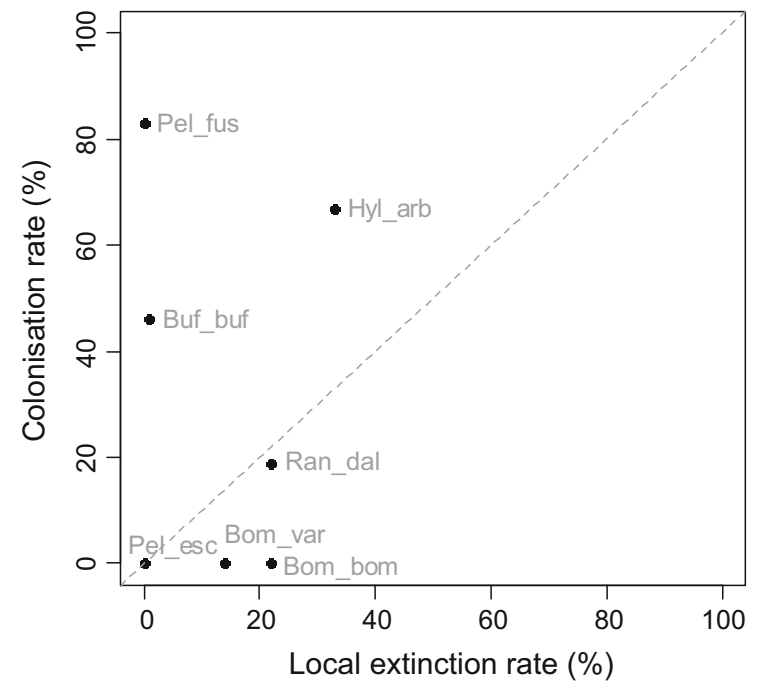

Fig. 4 Local colonisation and local extinction rates for each frog species. Dashed line represents 1:1 ratio of colonisation and extinction rates. Abbreviations for species (indicated only by labels with italic formatting) are derived from the first three letters of the genus and species name

(Snodgrass et al. 2000; Skelly 2001; Babbitt, Baber and Tarr 2003; Werner et al. 2007a). A number of studies have demonstrated that ponds with intermediate hydroperiod are optimal breeding sites for many amphibian species and thus tend to have high species richness (Wilbur 1980; Werner et al. 2007a). Our results were similar, with semi-permanent habitats having the highest richness (see Supplementary Table 1 in Online Resources). Many of these were totally dry during our first study year (2012).

Amphibian species richness decreases with decreasing landscape connectivity (caused by site isolation, road density or human land use; Lehtinen et al. 1999). In our case, landscape variables had only a minor effect on the assembly of communities. In a less fragmented landscape like our study area, forests can moderate the negative effects of intensive agriculture (Hartel et al. 2010; Knutson et al. 1999). Sheltered corridors with moist microclimate and wet substrate are very important during dispersal, especially for recently metamorphosed juveniles to avoid dehydration (Gibbs 1998). In our heterogeneous landscape, amphibian movements are less limited by human activities, which can altogether explain the overall low importance of landscape variables.

In general, temporal changes in metacommunity patterns and processes are largely unstudied. There are only a very few studies comparing vertebrate metacommunity drivers between years (fish in a stream network: Erős et al. 2012; birds: Bonthoux and Balent 2015). According to these, fish show much smaller interannual changes than the amphibian communities in our study, but the general dominance of local effects is similar. Bonthoux and Balent (2015) found that landscape variables explained bird metacommunity patterns better than pure spatial effects, with no pronounced temporal changes. These studies show that specialisation to different habitats (and the resulting strong species sorting) is a major factor in structuring vertebrate metacommunities in landscapes. However, compared to birds, amphibians have lower dispersal capabilities and therefore are much more affected by dispersal limitation; thus, they can show larger differences related to the actual number of habitat patches and the accessibility of the habitat matrix. Moreover, the type of the habitat networks can also influence the results: while our habitats represented isolated patches in the landscape, the habitat network of the investigated fish and bird communities was more continuous.

Species turnover and the role of body size

In amphibian communities, temporal turnover can be related to several mechanisms including extinctions, skipped breeding or adult breeding congregations that move between ponds (Werner et al. 2007b). Although any of them might have had an impact on our results, skipped breeding is the most probable explanation for the observed turnover, along with the effect of decreased connectivity. Low cumulative winterspring precipitation may result in spatially limited breeding activity in a region, restricted to a few ponds. In turn, high amounts of precipitation permit spatial expansion which is reflected by an increase in occupancy (Cayuela et al. 2012). Lower migration activity in relation to a low amount of precipitation in the breeding season was observed in several species (Sinsch 1988; Hartel 2008). Jakob et al. (2003) found in a Mediterranean pond system that some species skipped the breeding season when unfavourable hydrological conditions occurred. This behaviour likely played a role also in our case. March 2012 was the most arid period in the past 100 years in our study region (OMSZ 2014). The absence of rainfall with high temperatures in early spring most likely 
2012

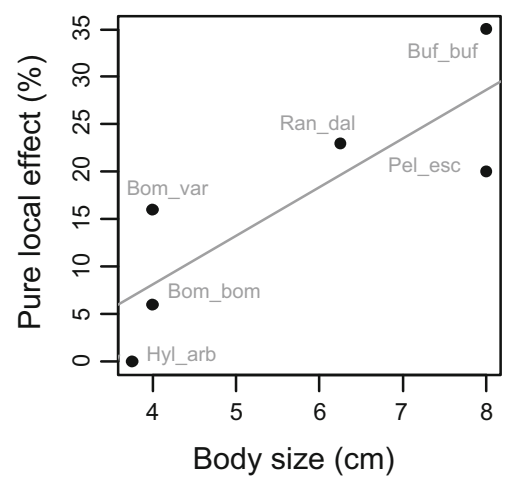

2013

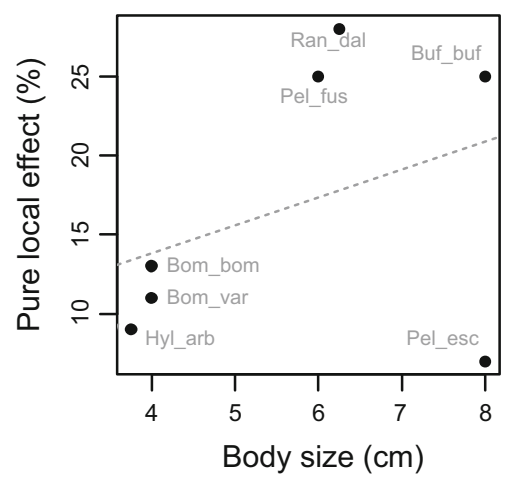

2012

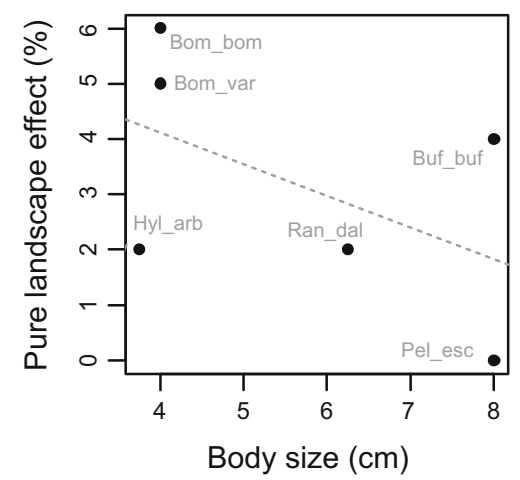

2013
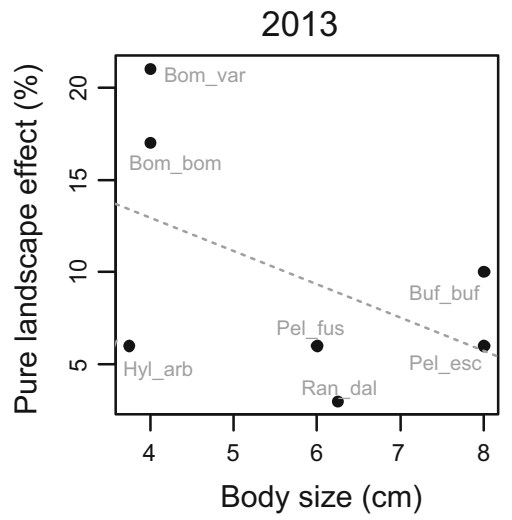

Fig. 5 Relationship between the pure local, landscape and spatial effect with body size (expressed in length) in 2012 and 2013. Dashed lines indicate the fitted non-significant linear models, while the solid line for local effects in 2012 indicates the

caused prolonged termination of hibernation for amphibians. This, together with the rainless autumn of 2011, produced a strong decline in the breeding activity of some species (e.g. Pelobates fuscus, Triturus dobrogicus), which were more numerous in the wet year. The same phenomenon was observed in the central part of the country in 2011-2012 (Németh et al. 2012).

Similarly to other studies (Jakob et al. 2003, Gómez-Rodríguez et al. 2010), we found that the variability of hydrological conditions highly affected temporal variation of the amphibian assemblages in the studied region. Werner et al. (2007b) found that area and hydroperiod were negatively related to turnover, whereas connectivity had a positive effect. In our case, higher amount of precipitation in the breeding season created not only additional habitats, which likely favoured amphibian dispersal by increasing connectivity, but these were at the same time more significant model. Abbreviations for species (indicated only by labels with italic formatting) are derived from the first three letters of the genus and species name

suitable breeding habitats (e.g. semi-permanent marshy areas, ponds with high productivity and without fish). Thus, our results suggest that dispersal limitation decreased in the wet year, when the available number and connectivity of habitats increased.

Local colonisation and extinction rates differed highly between the species. Bombina bombina is a real water frog spending the whole year in or near to the water and normally does not migrate more than $170 \mathrm{~m}$ within a season (Kovar et al. 2009). It was also found to be a relatively bad coloniser in our study. This implies its high vulnerability to regional extinctions with the disappearance and hence decreasing connectivity of its habitats, which may accelerate under climate change. B. variegata preferred brooks, puddles and wheel tracks at relatively high elevations (distinct from other species). Similarly to B. bombina, it did not appear in new ponds in 2013. This species is highly adapted to living in small waterbodies with 
short hydroperiod, and its movements between ponds decrease significantly with the increasing distance between the suitable habitat patches (Hartel 2008). The water frog $P$. esculentus complex showed the lowest $(0 \%)$ local colonisation and extinction rates (which means it was mostly present in the same habitats in both years), which is in accordance with the fact that this species depends on permanent waterbodies during the whole year. These water frogs hibernate underwater or in a nearby terrestrial location (Holenweg and Reyer 2000).

In contrast, we found higher rates of local colonisation for those species which only visit the waterbodies in the breeding season and migrate longer distances between ponds, summer habitats and hibernating sites. In our case, these were B. bufo, H. arborea and $P$. fuscus (Smith and Green 2005). In the case of $P$. fuscus, this pattern is in accordance with former studies. In a large-scale restoration in Estonia, where some old ponds were restored and many new ones created, the number of ponds occupied by $P$. fuscus increased by 6.5 times in only 3 years (Rannap et al. 2010).

All species showed spatial signals but to varying degrees. We found a negative tendency between the pure spatial effect and body size. Our results support the general theory that in actively dispersing taxa, larger species should be less dispersal limited (Jenkins et al. 2007). Additionally, we found a positive relationship between the pure local effect and body size, implying that larger species can find suitable habitat patches much easier than smaller species. This supports a general idea in metacommunity theory that the strength of species sorting and the match between species and their environment increase with decreasing dispersal limitation (Leibold et al. 2004). De Bie et al. (2012) found a negative relationship between the pure spatial and pure local components of community variance across multiple taxonomic groups involving amphibians. In contrast to our results, they found that larger species are more dispersal limited. This could be attributable to the fact that they mostly used data on passive dispersers, where the relationship between the size and dispersal ability is generally considered to be the opposite of the one seen in active dispersers (Vagvolgyi 1975; Shurin et al. 2009). In our case, the interspecific differences (relative positions of the species and hence the direction of the relationships in Fig. 5) did not change between the two years, even though the pure effect of space overall decreased in 2013. This also implies that these trait differences among species are stable and do not depend on environmental conditions.

Besides the obvious advantages of larger body size in dispersal, other organismal traits may also be responsible for this pattern. Generally, larger amphibian species lay more eggs than smaller ones and young amphibians are known to be more active dispersers than adults (Semlitsch 2008). Therefore, the number of metamorphosed juveniles may have also contributed to the relationship we found. The high number of active metamorphs in a year can also explain the low local extinction rates in the case of larger species.

\section{Conclusions}

According to our results, the role of both local and spatial effects can change between years. This caused no difference in the overall dominance of local variables in the explanation of community variation, but contributed to a huge difference in the relative strength of local against spatial effects (increasing from 20:6 to 18:1 in the wet year), which can be linked to the higher connectivity in the wet year.

We also provided evidence for the pronounced differences in the dispersal abilities of Central European amphibian species, related to their differences in body size and lifestyle. This has important implications for connectivity conservation with the goal of maintaining high regional amphibian diversity. Our results imply that the dispersal traits of different species should be taken into greater consideration in practical conservation decision-making. Dry years (with reduced connectivity due to drying out of temporary habitats) may have a pronounced negative effect especially on small-bodied amphibian species, as they seemed to be less effective dispersers compared to larger taxa.

Our results suggest that in such a heterogeneous landscape of Central Europe, landscape variables, including traditional land use-related effects, are of secondary importance. However, direct alteration of aquatic habitats and possible global warming-related changes in habitat connectivity could have serious consequences for amphibian metacommunities. Conserving a high diversity of habitats, especially semipermanent, highly productive ponds and marshes, 
together with maintaining connectivity (i.e. a high number of habitats in a region) is essential for the longterm protection of diverse amphibian communities. The creation of new pond networks could also be helpful for amphibian conservation, if based on the habitat requirements and dispersal ability of various amphibian species.

Acknowledgments We are grateful to Piet Spaak and four anonymous reviewers for providing useful comments and suggestions. We thank David Kurz and Dunja Lukić for the language revision. The research stay of A. L. Péntek at WasserCluster Lunz was supported by the short-term study program scholarship of Campus Hungary.

\section{References}

Babbitt KJ, Baber MJ, Tarr TL (2003) Patterns of larval amphibian distribution along a wetland hydroperiod gradient. Can J Zool 81:1539-1552

Bell G (1977) The life of the smooth newt (Triturus vulgaris) after metamorphosis. Ecol Monogr 47:279-299

Berninghausen F, Berninghausen O (1997) Welche Kaulquappe ist das?: Der wasserfeste Amphibienführer: Heimische Frösche, Kröten, Unken, Molche und Salamander auf 250 Fotos. Naturschutzbund Deutschland, Hannover p 43. Available at: www.whose-tadpole.net

Bonthoux S, Balent G (2015) Bird metacommunity processes remain constant after 25 years of landscape changes. Ecol Complex 21:39-43

Borcard D, Legendre P (2002) All-scale spatial analysis of ecological data by means of principal coordinates of neighbour matrices. Ecol Model 153:51-68

Cayuela H, Besnard A, BéChet A, Devictor V, Olivier A (2012) Reproductive dynamics of three amphibian species in Mediterranean wetlands: the role of local precipitation and hydrological regimes: reproductive dynamics of three amphibian species. Freshw Biol 57:2629-2640

Cottenie K (2005) Integrating environmental and spatial processes in ecological community dynamics. Ecol Lett 8:1175-1182

Curado N, Hartel T, Arntzen JW (2011) Amphibian pond loss as a function of landscape change-a case study over three decades in an agricultural area of northern France. Biol Conserv 144:1610-1618

De Bie T, Brendonck L, Martens K, Goddeeris B, Ercken D, Hampel H et al (2012) Body size and dispersal mode as key traits determining metacommunity structure of aquatic organisms. Ecol Lett 15:740-747

De Meester L, Declerck S, Stoks R, Louette G, Van De Meutter F, De Bie T et al (2005) Ponds and pools as model systems in conservation biology, ecology and evolutionary biology. Aquat Conserv: Mar Freshw Ecosyst 15:715-725

Delatorre M, Cunha N, Raizer J, Ferreira VL (2015) Evidence of stochasticity driving anuran metacommunity structure in the Pantanal wetlands. Freshw Biol 60:2197-2207
Erős T, Sály P, Takács P, Specziár A, Bíró P (2012) Temporal variability in the spatial and environmental determinants of functional metacommunity organization stream fish in a human-modified landscape. Freshw Biol 57:1914-1928

Ficetola GF, De Bernardi F (2004) Amphibians in a humandominated landscape: the community structure is related to habitat features and isolation. Biol Conserv 119:219-230

Fryer G (1985) Crustacean diversity in relation to the size of water bodies: some facts and problems. Freshw Biol 15:347-361

Google Inc. (2015) Available at: https://www.google.com/earth/

Gibbs JP (1998) Amphibian movements in response to forest edges, roads, and streambeds in southern New England. J Wildl Manage 62:584-589

Gómez-Rodríguez C, Díaz-Paniagua C, Serrano L, Florencio M, Portheault A (2009) Mediterranean temporary ponds as amphibian breeding habitats: the importance of preserving pond networks. Aquat Ecol 43:1179-1191

Gómez-Rodríguez C, Díaz-Paniagua C, Bustamante J, Portheault A, Florencio M (2010) Inter-annual variability in amphibian assemblages: implications for diversity assessment and conservation. Aquat Conserv: Mar Freshw Ecosyst 20:668-677

Hartel T (2008) Movement activity in a Bombina variegata population from a deciduous forested landscape. NorthWest J Zool 4:79-90

Hartel T, Oellerer K (2009) Local turnover and factors influencing the persistence of amphibians in permanent ponds from the Saxon landscapes of Transylvania. North-West J Zool 5:40-52

Hartel T, Schweiger O, Öllerer K, Cogalniceanu D, Arntzen JW (2010) Amphibian distribution in a traditionally managed rural landscape of Eastern Europe: probing the effect of landscape composition. Biol Conserv 143:1118-1124

Hartel T, Bancila R, Cogalniceanu D (2011) Spatial and temporal variability of aquatic habitat use by amphibians in a hydrologically modified landscape. Freshw Biol 56:2288-2298

Holenweg AK, Reyer HU (2000) Hibernation behavior of Rana lessonae and R. esculenta in their natural habitat. Oecologica 123:41-47

Houlahan JE, Findlay CS, Schmidt BR, Meyer AH, Kuzmin SL (2000) Quantitative evidence for global amphibian population declines. Nature 404:752-755

Jakob C, Poizat G, Veith M, Seitz A, Crivelli AJ (2003) Breeding phenology and larval distrbution of amphibians in a Mediterranean pond network with unpredictable hidrology. Hydrobiologia 499:51-61

Jenkins DG, Brescacin CR, Duxbury CV, Elliott JA, Evans JA, Grablow KR, Hillegass M, Lyon BN, Metzger GA, Olandese ML, Pepe D, Silvers GA, Suresch HN, Thompson TN, Trexler CM, Williams GE, Williams NC, Williams SE (2007) Does size matter for dispersal distance? Glob Ecol Biogeogr 16:415-425

Knutson MG, Sauer JR, Olsen DA, Mossman MJ, Hemesath LM, Lannoo MJ (1999) Effects of landscape composition and wetland fragmentation on frog and toad abundance and species richness in Iowa and Wisconsin, USA. Conserv Biol 13:1437-1446

Kovar R, Brabek M, Vikta R, Bocek R (2009) Spring migration distances of some Central European amphibian species. Amphibia-Reptilia 30:367-378 
Laan R, Verboom B (1990) Effects of pool size and isolation on amphibian communities. Biol Conserv 54:251-262

Lehtinen RM, Galatowitsch SM, Tester JR (1999) Consequences of habitat loss and fragmentation for wetland amphibian assemblages. Wetlands 19:1-12

Leibold MA, Holyoak M, Mouquet N, Amarasekare P, Chase JM, Hoopes MF et al (2004) The metacommunity concept: a framework for multi-scale community ecology. Ecol Lett 7:601-613

Logue JB, Mouquet N, Peter H, Hillebrand H (2011) Empirical approaches to metacommunities: a review and comparison with theory. Trends Ecol Evol 26:482-491

Marsh DM, Trenham PC (2001) Metapopulation dynamics and amphibian conservation. Conserv Biol 15:40-49

Németh A, Flórián N, Kavecsánszki A (2012) Kétéltümentés a 311-es közút farmosi szakaszán. Természetvédelem és kutatás a Tápió-vidéken, Rosalia 7

Oertli B, Joye DA, Castella E, Juge R, Cambin D, Lachavanne JB (2002) Does size matter? The relationship between pond area and biodiversity. Biol Conserv 104:59-70

Oksanen J, Blanchet FG, Kindt R, Legendre P, Minchin PR, O'Hara RB, Simpson GL, Solymos P, Stevens MHH, Wagner H (2012) vegan: Community Ecology Package. R package version 2.0

OMSZ (2014) Avaliable at: http://www.met.hu/en

Pechmann JH, Estes RA, Scott DE, Gibbons JW (2001) Amphibian colonization and use of ponds created for trial mitigation of wetland loss. Wetlands 21:93-111

Provete DB, Gonçalves-Souza T, Garey MV, Martins IA, Rossa-Feres DC (2014) Broad-scale spatial patterns of pond morphology and canopy cover affect the structure of Neotropical tadpole metacommunity. Hydrobiologia 734:69-79

Puky M, Schád P, Szövényi G (2005) Herpetological atlas of Hungary. Varangy Akciócsoport Egyesület, Budapest

R Development Core Team (2009) R: a language and environment for statistical computing. R Foundation for Statistical Computing, Vienna, Austria. Available at: http://www.Rproject.org/

Rannap R, Lohmus A, Briggs L (2010) Restoring ponds for amphibians: a success story. Pond Conserv Eur 210:243-251

Richter-Boix A, Llorente GA, Montori A (2007) Structure and dynamics of an amphibian metacommunity in two regions. J Anim Ecol 76:607-618

Rubbo MJ, Kiesecker JM (2005) Amphibian breeding distribution in an urbanized landscape. Conserv Biol 19:504-511

Schwartz SS, Jenkins DG (2000) Temporary aquatic habitats: constraints and opportunities. Aquat Ecol 34:3-8

Semlitsch RD (ed) (2003) Amphibian conservation. Smithsonian Books, Washington

Semlitsch RD (2008) Differentiating migration and dispersal processes for pond-breeding amphibians. J Wildl Manage 72:260-267

Shurin JB, Cottenie K, Hillebrand H (2009) Spatial autocorrelation and dispersal limitation in freshwater organisms. Oecologia 159:151-159
Sinsch U (1988) Seasonal changes in the migratory behaviour of the toad Bufo bufo: direction and magnitude of movements. Oecologia 76:390-398

Skelly DK (2001) Distributions of pond-breeding anurans: an overview of mechanisms. Isr J Zool 47:313-332

Skelly DK, Freidenburg LK, Kiesecker JM (2002) Forest canopy and the performance of larval amphibians. Ecology 83:983-992

Smith MA, Green DM (2005) Dispersal and the metapopulation paradigm in amphibian ecology and conservation: are all amphibian populations metapopulations? Ecography 28:110-128

Smith MA, Green DM (2006) Sex, isolation and fidelity: unbiased long-distance dispersal in a terrestrial amphibian. Ecography 29:649-658

Snodgrass JW, Komoroski MJ, Bryan AL, Burger J (2000) Relationships among isolated wetland size, hydroperiod, and amphibian species richness: implications for wetland regulations. Conserv Biol 14:414-419

Soininen J, Lennon JJ, Hillebrand H (2007) A multivariate analysis of beta diversity across organisms and environments. Ecology 88:2830-2838

Strijbosch H (1979) Habitat selection of amphibians during their aquatic phase. Oikos 33:363-372

Stuart SN, Chanson JS, Cox NA, Young BE, Rodrigues AS, Fischman DL et al (2004) Status and trends of amphibian declines and extinctions worldwide. Science 306:1783-1786

Vági B, Kovács T, Bancila R, Hartel T, Anthony B (2013) A landscape-level study on the breeding site characteristics of ten amphibian species in Central Europe. Amphib-Reptil 34:63-73

Vagvolgyi J (1975) Body size, aerial dispersal, and origin of the Pacific land snail. Fauna Syst Zool 24:465-488

Van Buskirk J (2005) Local and landscape influence on amphibian occurrence and abundance. Ecology 86:1936-1947

Venables W, Ripley YB (2002) Modern applied statistics using S. Springer, New York

Vos CC, Chardon JP (1998) Effects of habitat fragmentation and road density on the distribution pattern of the moor frog Rana arvalis. J Appl Ecol 35:44-56

Welborn GA, Skelly DK, Werner EE (1996) Mechanisms creating community structure across a freshwater habitat gradient. Annu Rev Ecol Syst 27:337-363

Werner EE, Skelly DK, Relyea RA, Yurewicz KL (2007a) Amphibian species richness across environmental gradients. Oikos 116:1697-1712

Werner EE, Yurewicz KL, Skelly DK, Relyea RA (2007b) Turnover in an amphibian metacommunity: the role of local and regional factors. Oikos 116:1713-1725

Weyrauch SL, Grubb TC Jr (2004) Patch and landscape characteristics associated with the distribution of woodland amphibians in an agricultural fragmented landscape: an information-theoretic approach. Biol Conserv 115:443-450

Wilbur HM (1980) Complex life cycles. Annu Rev Ecol Syst 11:67-93 